\title{
NATURALEZA E HISTORIA EN LA VISIÓN DEL PAISAJE DE LA INSTITUCIÓN LIBRE DE ENSEÑANZA: EL REAL SITIO DE LA GRANJA DE SAN ILDEFONSO ${ }^{1}$
}

\author{
Nicolás Ortega Cantero \\ Universidad Autónoma de Madrid
}

\section{RESUMEN}

Francisco Giner de los Ríos (1839-1915) y sus colaboradores de la Institución Libre de Enseñanza, fundada en Madrid en 1876, introdujeron en España el modo geográfico de valorar el paisaje inicialmente promovido por Humboldt. Ese modo moderno de ver el paisaje estuvo asociado a una concepción igualmente moderna de las excursiones, que ocuparon un lugar muy destacado en el horizonte intelectual y educativo de Giner y la Institución. Las excursiones prestaron atención tanto a los aspectos naturales como a los testimonios históricos, monumentales y artísticos, del paisaje, y ambas atenciones se expresaron ejemplarmente en sus acercamientos a La Granja de San Ildefonso, en la Sierra de Guadarrama. Este artículo, apoyado en el análisis y la interpretación contextualizada de los textos de diversa índole relacionados con el asunto, estudia las claves de la valoración de esos aspectos naturales e históricos del paisaje de La Granja de San Ildefonso en los sucesivos acercamientos al lugar de los institucionistas, desde su primera excursión a la Sierra de Guadarrama en 1883, hasta las vísperas de la última guerra civil.

Palabras clave: Institución Libre de Enseñanza, geografía moderna, valoración del paisaje, naturaleza, historia, Real Sitio de La Granja de San Ildefonso.

\section{ABSTRACT}

Nature and history in the vision of landscape of the Institución Libre de Enseñanza: the Royal Site of La Granja de San Ildefonso.

1. Este trabajo se ha realizado dentro del Proyecto de Investigación CSO2012-38425, financiado por el Ministerio de Economía y Competitividad. 
Francisco Giner (1839-1915) and his colleagues at the Institución Libre de Enseñanza, founded in Madrid in 1876, introduced in Spain the perspective of modern view of the geographical landscape, initially promoted by Humboldt. This modern way of seeing the landscape was associated with an equally modern conception of the excursions, which occupied a very prominent place in the intellectual and educational horizon of Giner and the Institución. Excursions paid much attention to the natural aspects as historical, monumental and artistic features of the landscape, and were both expressed exemplary in their approaches to La Granja de San Ildefonso, in the Sierra de Guadarrama.This article, supported by analysis and contextual interpretation of texts of diverse nature related to the topic, studies the key of the assessment of those natural and historical aspects of the landscape of La Granja de San Ildefonso in the successive approaches to the place of the Institución Libre de Enseñanza, from his first excursion to the Sierra de Guadarrama in 1883, until the eve of the last civil war.

Keywords: Institución Libre de Enseñanza, modern geography, assessment of the landscape, nature, history, Royal Site of La Granja de San Ildefonso.

\section{EXCURSIONISMO Y VALORACIÓN DEL PAISAJE}

Las relaciones entre los miembros de la Institución Libre de Enseñanza y La Granja de San Ildefonso se iniciaron durante su primera excursión a la Sierra de Guadarrama en el verano de 1883. Esta excursión, importante por varias razones, abrió el camino de todo el excursionismo posterior desarrollado por la Institución, a lo largo de sus sesenta años de existencia, en la Sierra de Guadarrama. Fue una excursión muy innovadora, en la que se puso en práctica por vez primera en España una nueva manera, enteramente moderna, de entender la naturaleza y el paisaje. Y esa excursión fue el fundamento de la nueva imagen del paisaje de la Sierra de Guadarrama ofrecida por la Institución Libre de Enseñanza. Precisamente en esa excursión se produjo el descubrimiento institucionista de la Sierra de Guadarrama, incluyendo el de La Granja de San Ildefonso. No está de más, por tanto, que comencemos por decir algo de esa excursión, de las razones de su interés y de su importancia, y que la situemos en el marco de las ideas y las actitudes promovidas, desde su fundación, por la Institución Libre de Enseñanza.

La Institución Libre de Enseñanza fue fundada, en Madrid, en 1876, por un grupo de profesores de universidad y de instituto, que habían sido expulsados de sus puestos docentes (y en ocasiones desterrados) por negarse a aceptar las directrices contrarias a la libertad de enseñanza impuestas poco antes, al comenzar la Restauración, por el ministro Orovio. Entre esos profesores se encontraban Francisco Giner de los Ríos, catedrático de la Universidad de Madrid y principal impulsor de la Institución, Eugenio Montero Ríos, Segismundo Moret, Nicolás Salmerón, Augusto González de Linares y Gumersindo de Azcárate. 
Tras el fracaso del denominado sexenio democrático (1868-1874), esos profesores llegaron a la conclusión de que la reforma social y política sólo sería posible cuando se hubiese reformado antes y a fondo la forma de ser y de actuar de quienes debían ponerla en práctica. La clave de cualquier reforma seria de la sociedad debía ser, en su opinión, la reforma educativa, y, en consecuencia, lo primero que había que hacer, como dijo Francisco Giner, era «formar hombres» (Giner de los Ríos, 2004b: 290). Y precisamente para eso, para llevar a cabo esa reforma y esa formación de hombres, se fundó la Institución Libre de Enseñanza, un centro educativo profundamente renovador, preferentemente dedicado a la segunda enseñanza, interesado en educar -no solo en instruir- a sus alumnos, y que tuvo carácter privado para evitar las injerencias perturbadoras del poder político, que todos ellos habían sufrido con la expulsión de sus cátedras.

A lo largo de sus sesenta años de existencia -desde que se fundó, en 1876, hasta que tuvo que cerrar sus puertas, en 1936-, la Institución Libre de Enseñanza fue un centro educativo en el que se llevó a cabo una profunda renovación de la enseñanza. Su labor resultó, en ese terreno, muy importante y muy influyente, hasta el punto de que Juan López-Morillas pudo decir que fue «el acontecimiento pedagógico de mayor resonancia en la historia de la cultura española moderna» (López-Morillas, 1972: 244). Pero su obra no se redujo al terreno pedagógico. La Institución constituyó un núcleo intelectual muy activo, cuya presencia e influencia se dejó sentir con fuerza en otros ámbitos de la vida intelectual y política del país. Impulsó una amplia modernización del panorama científico y cultural de la España de su tiempo, introduciendo y desarrollando los planteamientos más actualizados de otros países.

En todas sus actuaciones, la Institución Libre de Enseñanza siguió con fidelidad los criterios y las directrices de Francisco Giner, que se mostró siempre partidario de prestar mucha atención a los «progresos» de otras naciones, e incorporarlos, con las adaptaciones precisas pero sin desvirtuar su sentido, al propio quehacer (Giner de los Ríos, 2004a: 267). Giner y la Institución conocieron bien lo que ocurría en otros países europeos, estuvieron siempre atentos a los movimientos foráneos que intentaron mejorar, desde principios del siglo XIX, el modo de entender y de practicar la enseñanza, el estudio y la investigación. Y en el acercamiento a Europa, en la europeización, vieron Giner y sus colaboradores de la Institución un camino seguro para avanzar hacia los fines renovadores que perseguían. Era, ante todo, un modo de incorporar al panorama español las claves mayores, los fundamentos, de la cultura europea. Se trataba de asimilar el carácter de esa cultura europea -su «sustancia», como dijo López-Morillas (1980: 29-30), no sus «accidentes» o sus «formas aisladas»-, de aceptar las pautas intelectuales en las que se apoyaba, y de utilizar además sus posibilidades para modernizar, en ese orden de cosas, la situación española. 
Realizaron así una labor de auténtica europeización, de incorporación de las claves mayores de la cultura europea, pero sin olvidarse por ello de la debida valoración de lo español. Se quiso -y se logró-aunar la innovación y la tradición, hermanar lo propio y lo foráneo. Había en la Institución, como decía Azorín, «una nota de universalidad y otra nota de españolismo», y ambas se hallaban igualmente presentes en el pensamiento de su principal impulsor: «Giner y su europeísmo -escribe Azorín-, aliado al amor por el paisaje de Castilla. Giner, europeo y apasionado del Guadarrama» (Azorín, 1967: 124 y 127). Con esa perspectiva de europeización, con ese deseo de introducir en España las claves de la cultura europea de su tiempo, se relaciona directamente la visión del paisaje ofrecida por Giner y, siguiendo sus pasos, por la Institución Libre de Enseñanza. Ésta fue una aportación fundamental y muy valiosa, que influyó decisivamente en todo el paisajismo español posterior.

Giner incorporó y desarrolló, con notable perspicacia, los rasgos característicos del modo moderno de entender el paisaje, y tuvo muy en cuenta, dentro de ese horizonte, los puntos de vista promovidos, desde tiempos de Humboldt, por la geografía. Las actitudes y las intenciones que presiden estos puntos de vista geográficos, con su expreso interés en buscar la convergencia de enfoques distintos pero complementarios, su empeño en apoyarse en lo que se ha denominado «movilidad de la mirada» (Berdoulay y Saule-Sorbé, 1998), están muy presentes en el modo de acercarse al paisaje y entenderlo que propuso Giner. Basta comparar su visión del paisaje con las que estaban ofreciendo, en los mismos años, fuera de España, algunos geógrafos y paisajistas coetáneos, como Élisée Reclus o Franz Schrader, para comprobar la proximidad entre una y otras, y la plena pertenencia de Giner al horizonte de la modernidad paisajística europea.

De ese modo, incorporando las notas distintivas de ese horizonte, pudo Giner renovar sustancialmente la visión del paisaje español. Acertó a proponer una imagen moderna de ese paisaje, una nueva manera de verlo y de valorarlo, y dirigió especialmente su atención, en ese sentido, hacia Castilla, el paisaje de Castilla, y, en particular, hacia la Sierra de Guadarrama. Y a ello se asoció, sin que sea posible separar una cosa de otra, su afición a las excursiones, su dedicación al excursionismo, en el que vio, coincidiendo también en ello con las tendencias de la modernidad europea, un medio insustituible para lograr, entre otras cosas, el conocimiento directo del paisaje. En las excursiones se apoya el modo renovado de entender el paisaje que ofrece Giner, indisociable de su práctica del excursionismo. Y todo ese planteamiento arraigó firmemente en la Institución Libre de Enseñanza, que impulsó en todo momento el modo de ver el paisaje y de realizar las excursiones que había propuesto inicialmente Francisco Giner. Uno y otra, Giner y la Institución, contribuyeron así a abrir en España la puerta a la consideración moderna del paisaje y a la práctica, resuelta también en términos modernos, del excursionismo (Ortega Cantero, 2001: 17-34 y 61-106). 
Como ocurre siempre en este tipo de asuntos, la visión del paisaje elaborada por el círculo gineriano e institucionista mantiene estrechas relaciones con su ideario y con sus aspiraciones, con su forma de entender la situación del país, de valorar su pasado y su presente, y de imaginar las soluciones que consideraban más adecuadas para sus problemas. La imagen del paisaje habla siempre de lo que cree y espera quien la ofrece. «El paisaje somos nosotros», decía Azorín (1917: 43). Y dos geógrafos dijeron hace algún tiempo que el paisaje entraña siempre una «imagen cultural», una manera de representar, ordenar o simbolizar el mundo que nos rodea (Daniels y Cosgrove, 1988: 1). Y también en el campo geográfico, se ha afirmado que el paisaje es un espejo en el que nos reflejamos nosotros mismos, y en el que «creamos, más allá del sentido de las cosas, el sentido del mundo» (Rochefort, 1978: 243). Las cualidades que Francisco Giner y los institucionistas descubren en el paisaje, los valores y los significados que le atribuyen, son inseparables de su pensamiento y de sus creencias. La imagen del paisaje forma parte de su imaginario, del conjunto de representaciones que expresan simbólicamente la concepción del mundo que les rodea y de las posibilidades de mejorarlo.

En ese sentido, la visión del paisaje promovida por Giner y por la Institución Libre de Enseñanza se halla directamente conectada con su participación en el proceso de identificación de la comunidad nacional, de signo liberal, que se estaba desarrollando entonces en España. Acercarse al paisaje era un modo de acercarse al pueblo español, a su carácter y a su historia. La consideración del paisaje ocupó así un lugar destacado en el horizonte historiográfico del círculo gineriano e institucionista, y lo ocupó también a la hora de entender y procurar descubrir, de acuerdo con ese horizonte, los rasgos característicos de la propia identidad nacional. El modo de entender el paisaje, lo mismo que el modo de entender las excursiones, comprendía, en Giner y en sus compañeros de la Institución, una clara intención de afirmación nacional, de búsqueda de las notas distintivas, propias, de la identidad nacional española. No ignoraron ni ocultaron nunca esa dimensión: al contrario, insistieron una y otra vez en el sentido patriótico que atribuían a sus iniciativas en pro del acercamiento al paisaje y del desarrollo del excursionismo. No estaba lejos esa relación de los planteamientos de algunos geógrafos foráneos: basta leer, por ejemplo, a Paul Vidal de la Blache, y prestar atención a las conexiones que establece, a finales del siglo XIX y principios del xx, en el caso de Francia, entre el carácter del paisaje y la identidad nacional, para comprobarlo.

La perspectiva de Giner y de los institucionistas, acorde en lo fundamental con los puntos de vista de la geografía moderna, afirma que existen hondas relaciones entre el paisaje y los hombres. Es éste un aspecto sumamente importante en ese horizonte, ya que en la existencia de tales relaciones se apoya la destacada importancia que adquiere el conocimiento del paisaje, el entendimiento de 
sus cualidades y de sus significados, a la hora de descubrir los rasgos peculiares del carácter del pueblo español, las claves de la comunidad nacional. Existe solidaridad entre los hombres y el paisaje, y esa solidaridad, que se manifiesta en términos individuales y colectivos, es la que hace del segundo un valioso testimonio para entender el carácter de los primeros. Conocer el paisaje es un medio de conocer a los hombres que lo habitan, de poner en claro los rasgos distintivos de su carácter. Porque, de acuerdo con esta perspectiva, los rasgos característicos de los pueblos están relacionados con los paisajes en los que viven y se desenvuelven. El paisaje, con sus permanencias, adquiere significado histórico, aporta una ayuda valiosa para identificar las características del propio pasado. En el horizonte historiográfico gineriano e institucionista, deudor de las ideas de Herder y Krause, interesado siempre en descubrir, bajo la superficie de la historia externa u oficial, la historia interna o intrahistoria del pueblo español, la que se identifica con su carácter o psicología, con su cultura colectiva, la consideración del paisaje es también un modo de acercarse a la comprensión del propio pasado.

Al igual que ocurre con el arte o la literatura, el paisaje nos acerca a la caracterización intrahistórica del pueblo español, al conocimiento de los rasgos más genuinos de su espíritu y de su tradición cultural. Es lo que advirtió Rafael Altamira al afirmar que Giner supo sentir el paisaje castellano «con una emoción tan honda y una tan grande claridad de concepto, que le llevaron hasta la más profunda raíz de patriotismo que emana de la tierra en que formó un pueblo su alma y su historia» (Altamira, 1921: 220). Por todo ello, las excursiones no fueron sólo, para Giner y los institucionistas, un instrumento pedagógico importante, sino también, al tiempo, un medio muy valioso para mejorar el conocimiento del propio país, de su patrimonio natural, histórico y artístico. Y consideraron además que ese conocimiento directo de la realidad española era fundamental para conformar una verdadera conciencia nacional, para vertebrar un patriotismo sólido y responsable. Las excursiones eran un medio particularmente valioso para acercarse a las claves -naturales, históricas, artísticas- de la comunidad española, a los rasgos característicos de la propia identidad nacional. La actividad excursionista fue, en la Institución, inseparable de los afanes de afirmación nacional, de búsqueda de las notas distintivas de la nacionalidad española, que acompañaron a toda su labor.

Uno de los ejemplos más claros de la gran importancia que concedió el círculo gineriano e institucionista a las excursiones como medio para lograr un mejor conocimiento de la realidad española y una mayor conciencia nacional se encuentra en los principios fundacionales de la Sociedad para el estudio del Guadarrama, constituida en 1886, dentro de la Institución Libre de Enseñanza, bajo la dirección del naturalista José Macpherson. Las excursiones desempeñan, según los fundadores de la nueva Sociedad, un papel importante tanto en la 
mejora «del estudio, de la enseñanza y de la ciencia», ya que hacen posible «el examen directo e inmediato de las cosas para conocerlas», como en la conformación de un "verdadero y legítimo patriotismo», apoyado en «el estudio real y positivo de España» (Sociedad para el estudio del Guadarrama, 1886: 367).

Las excursiones de Francisco Giner y de la Institución Libre de Enseñanza tuvieron dos propósitos principales, que a veces se plantearon por separado y en otras ocasiones de forma conjunta y complementaria: por una parte, ponerse en contacto directo con la naturaleza y el paisaje, acercarse al patrimonio natural español; y, por otra parte, ponerse en contacto directo con el arte, aproximarse al patrimonio artístico e histórico español. Naturaleza y paisaje, por un lado, y aspectos históricos y artísticos, por otro, señalan las direcciones fundamentales de sus excursiones. La atención prestada a los aspectos históricos y artísticos fue tan grande como la que dedicaron a la naturaleza y al paisaje. Las excursiones fueron para ellos un medio muy valioso para mejorar el conocimiento del propio patrimonio artístico, para entender mejor el valor y el significado de los monumentos y obras de arte conformados a lo largo de la propia historia. Y eso tenía una importancia grande en el horizonte historiográfico del círculo gineriano e institucionista, que consideraba que en las expresiones artísticas podían encontrarse las claves de la historia y de la cultura del pueblo español. El arte español, decía Manuel Bartolomé Cossío, lleva impreso «el sello nacional», muestra el carácter del pueblo del que procede, «los rasgos distintivos y peculiares del genio del país» (Cossío, 1985: 33). Y Alberto Jiménez Fraud recordaba las continuas excursiones de Cossío «a ciudades históricas, a pueblos apartados, a palacios, conventos y rincones olvidados de toda España, en busca y descubrimiento de bellezas con que iba reconstruyendo la gloriosa participación de España en la historia del arte». Era, añadía, un modo de acercarse a «la historia artística de su país, aprendiendo a interpretar a través de ella la historia viva-social, como hoy diríamos-del pueblo español» (Jiménez, 1948: 200-201).

La atención a la historia y al arte se compaginó con frecuencia en las excursiones de la Institución con la atención dedicada a la naturaleza y al paisaje. Esa doble atención, importante para mejorar el conocimiento de España y promover consecuentemente una conciencia nacional más sólida, estuvo muy presente, por ejemplo, en la amplia serie de excursiones de la Institución que dirigieron José Giner Pantoja y José Ontañón Valiente. En los relatos de esas excursiones publicados en el Boletín, escribieron lo siguiente: «En nuestras excursiones, ha presidido siempre el afán de dar la misma importancia al Arte que a la Naturaleza, queriendo constantemente hacer ver la íntima relación entre uno y otra, y el de poner de relieve todo cuanto tiene carácter peculiar en nuestro suelo y toda huella que de la Historia de España nos hemos encontrado» (Giner y Ontañón, 1932: 29). 
En ese marco general se situaron las numerosas excursiones que Giner y sus compañeros de la Institución hicieron a la Sierra de Guadarrama. Y, entre ellas, fue especialmente significativa la primera, la que llevaron a cabo en julio de 1883, en la que se aunaron ejemplarmente las curiosidades complementarias hacia la naturaleza y el paisaje y hacia los aspectos históricos y artísticos. Fue el primer eslabón del «descubrimiento» moderno de los valores naturales, históricos y culturales del Guadarrama, y constituyó un verdadero modelo para quienes se acercaron, desde entonces, a la Sierra. Atribuyeron al paisaje de la Sierra de Guadarrama, además, un elevado valor simbólico. Vieron en su paisaje, y, especialmente, en algunos de sus lugares principales -Peñalara, el valle del Lozoya, la Cartuja del Paular-, un símbolo nacional, un símbolo de la propia historia y de la propia cultura. La Sierra de Guadarrama estuvo así muy presente en el proceso de simbolización asociado a la labor del círculo gineriano e institucionista y a su búsqueda de las claves de la identidad nacional española. Apoyándose en su experiencia personal de esa excursión, Giner ofreció la primera imagen moderna de la Sierra de Guadarrama en un artículo que fue, por muchas razones, fundamental -y fundacional respecto del paisajismo español moderno-: el titulado «Paisaje», publicado inicialmente en 1886 (Giner de los Ríos, 2004c). En él se puede distinguir la convergencia de la mirada explicativa, interesada ante todo por la caracterización y las relaciones mutuas del relieve y la vegetación, y la mirada comprensiva, capaz de descubrir aquellos valores y significados -fuerza interior, severa grandeza, nobleza, dignidad, señorío- que descubrió Giner en el paisaje castellano, tanto el de la montaña, la Sierra de Guadarrama, como el del llano (Ortega Cantero, 2012).

\section{LA EXCURSIÓN DE 1883 Y EL ACERCAMIENTO A LA GRANJA}

Pasemos ya, una vez dicho lo anterior, a hablar de la excursión de 1883 y del descubrimiento de La Granja que se produjo en ella. El Boletín institucionista publicó después, entre diciembre de 1886 y mayo de 1887 , en siete entregas sucesivas, un relato bastante pormenorizado de casi todo ese recorrido por la Sierra de Guadarrama (Excursión, 1886-1887). La narración, inconclusa, comprende cuatro días, desde la salida de Madrid hasta la llegada a La Granja, y aporta un testimonio sumamente valioso del modo que tenían Giner y sus compañeros de la Institución de entender las excursiones y de acercarse, a través de ellas, al paisaje. A ese testimonio escrito se añadió después otro, debido a José Madrid Moreno, que participó también en la excursión, más completo cronológicamente pero mucho más esquemático, que incluye también la parte dedicada a La Granja y Segovia, que se publicó en 1931 en la revista Peñalara (Madrid Moreno, 1931). 
El grupo que llevó a cabo esa excursión a la Sierra de Guadarrama del verano del 83 estaba formado por catorce personas: Francisco Ginery Manuel Bartolomé Cossío, que lo encabezaban, otros tres colaboradores de la Institución -el naturalista Salvador Calderón, que era entonces catedrático de Historia Natural del Instituto de Segovia, el también naturalista José Madrid Moreno y Jerónimo Vida-, y nueve alumnos, entre los que se encontraba Julián Besteiro, que tenía entonces 12 años, el futuro presidente socialista de las Cortes Constituyentes de la Segunda República. Años después, en junio de 1932, siendo ya presidente de las Cortes, asistió Besteiro a la inauguración de la Fuente de los Geólogos, y recordó el significado de la excursión de 1883:

Cuando yo tenía 13 [sic] años, mis compañeros y yo seguíamos por estos caminos a nuestros maestros, y aquellos jóvenes maestros seguían a D. Francisco Giner, y al nuevo espíritu que D. Francisco Giner trataba de infundir en el país. $[\ldots]$

Y animados por aquel espíritu nuevo, seguían a D. Francisco Giner por estas montañas los maestros jóvenes, y les seguíamos también un puñado de niños, animados de un entusiasmo que nos hacía realizar empresas tal vez superiores a nuestras fuerzas, y cuya significación solamente hoy podemos comprender plenamente. [...]

Sin saberlo nosotros, íbamos buscando por estos montes, no a la serrana del Arcipreste, sino la nueva España del porvenir (Besteiro, 1932: 239-240).

También en ese acto de inauguración de la Fuente de los Geólogos, Cossío recordó la excursión de 1883 y el papel que habían desempeñado en ella los tres geólogos homenajeados allí, José Macpherson, Salvador Calderón y Francisco Quiroga, profesores los tres de la Institución: de la preparación en clase de alumnos y profesores para la excursión se encargaron Macpherson y Quiroga, Calderón participó personalmente -como «maestro geólogo», en palabras de Cossío- en el recorrido de los excursionistas por el Guadarrama, y la excursión se hizo con los mapas - calcos y croquis a dos colores, conservados en la Institución- que había dibujado Macpherson (Cossío, 1932: 238), ya que la cartografía topográfica de la zona de la excursión todavía no existía: las hojas 483 (Segovia) y 508 (Cercedilla) del Mapa Topográfico Nacional 1:50.000 se editaron respectivamente en 1927 y 1923.

Salieron de la estación del Norte de Madrid el día 14 de julio, sábado, a las siete y media de la tarde, y el tren los dejó una hora después en Villalba -que era entonces la estación de ferrocarril más próxima a la Sierra, hasta la apertura en 1888 del tramo Villalba-Segovia, con estación en Cercedilla-, donde durmieron. Al día siguiente, domingo, caminaron desde allí hasta el valle del Lozoya, pasando por los puertos de Navacerrada y de Cotos, y durmieron en un pequeño establo. Dedicaron el lunes a andar por el valle, hasta llegar a Rascafría, donde se hospedaron, y a visitar la Cartuja del Paular. El día 17, martes, pasaron, por 
el puerto del Reventón, a La Granja y visitaron el Palacio, para continuar luego el camino hasta Segovia. Recorrieron allí, durante dos días y medio, los monumentos artísticos de la ciudad, y el viernes, a primera hora de la tarde, regresaron a La Granja, donde pasearon por los jardines y pasaron la noche. Otra larga caminata los llevó al día siguiente, sábado, hasta la estación de Villalba, para coger, ya de noche, el tren de Valladolid, y proseguir el viaje por el Norte de España.

El relato publicado en el Boletín de la Institución informa con detalle del recorrido y de los muy variados aspectos que fueron llamando la atención de los excursionistas. A lo largo de su caminata, los excursionistas prestaron atención a los rasgos naturales del paisaje, y también a los aspectos humanos, a las huellas que había ido dejando en él la acción de los hombres. Les interesaron mucho los nombres con que son conocidos los lugares, las casas, los caminos y las formas naturales que van encontrando. Veamos un ejemplo, que se refiere al paisaje segoviano. Una vez pasado el puerto del Reventón, ya en la provincia de Segovia, hablando del descenso hacia La Granja, la narración del Boletín ofrece una de las muestras más elocuentes de su interés simultáneo por la caracterización natural del paisaje y por los nombres con que son conocidos los elementos que lo componen:

Despedimos al guía -que hace poca falta, porque las veredas no tienen pérdida hasta el puerto-y comenzamos la bajada de la vertiente N., a las $10^{\mathrm{h}}$ y $30^{\mathrm{m}}$, por un camino sumamente quebrado y sin ninguna vegetación. A poco, bebimos agua, ya de la cuenca del Duero, en la fuente de Infantes, que nace en unos prados húmedos llamados trampales, que, poco a poco, se convierten en turberas, frecuentes en esta región subalpina de la sierra, y en las cuales suelen tener su origen los arroyos, sobre todo cuando hay gran cantidad de agua con la turba: entonces de llaman tollas. Continuamos por la vereda, a la orilla izquierda de la canal que forman las aguas de aquella fuente, que más adelante reciben el nombre de Arroyo del Chorro grande, y en el sitio en que éste se despeña en cascadas por un ancho cauce de gneis cubierto de líquenes, teñido por óxido de hierro y de aspecto muy pintoresco, pareciéndonos que habíamos perdido el camino y que dejábamos La Granja al S. Cruzamos en esta dirección la divisoria del macizo de Chorro grande, que con Peñas Buitreras al N. forma la estribación occidental del Reventón, y entramos en la canal del Arroyo Morete, por donde seguimos ya sin dificultad hasta llegar al monte bajo de roble, que llaman en general Las Matas, donde descansamos a las $2^{\mathrm{h}} 15^{\mathrm{m}}$ de la tarde. Temperatura: $30{ }^{\circ}, 5$. La bajada fue fatigosa, especialmente por haberla hecho casi toda fuera del camino que desde La Granja conduce a Rascafría por este punto, y que nosotros perdimos. Al pasar de una a otra canal, dimos con una torada que nos obligó a dispersarnos y a marchar con recelo. Allí observamos la dirección de las capas de gneis, resultando de NNO. a SSE., con buzamientos de SO. a NE., en un ángulo de 35 grados. 
El interés por el paisaje, por sus componentes naturales y humanos, se manifiesta con claridad meridiana a través de la imagen que ofrece el relato de la excursión de 1883 del valle del Lozoya. En su cabecera, tras bajar desde la Hoya del Toril, junto a la base de las Dos Hermanas, se habla del «paisaje imponente y severo por la estrechez del valle, las enormes masas de ambas vertientes, la espesura del pinar y el río despeñándose con verdadero estrépito.» (Excursión, 18861887: XI, 32). Y poco después, a propósito de su paso por Rascafría, se dice en el relato que el hijo del posadero les dio «noticias del pueblo»: doscientos cincuenta vecinos, una escuela de niños y otra de niñas, el trabajo de algunos en la fábrica de papel y en el aserradero, la caza del corzo durante el largo invierno, la escasa riqueza que allí había, y los cultivos principales, «centeno y patatas y un cereal, variedad del trigo, más sabroso y menos nutritivo que éste, y al cual llaman tresmesino por dar su producto en tres meses» (Excursión, 1886-1887: XI, 143). Otros detalles se añaden a ese rápido apunte: la necesidad de madrugar para encontrar leche -era «difícil hallarla, a no ser por la mañana temprano»-, o el papel abastecedor de la «magnífica» huerta de la Cartuja, «que surte de fruta al valle, donde apenas hay más que la del Convento» (Excursión, 1886-1887: XI, 128 y 143).

Se habla también en el relato del pueblo de Rascafría, y se ofrece una descripción escueta y lograda, expresiva y evocadora al tiempo, de la posada en la que se alojaron, que permite hacerse una idea de lo que era entonces la casa rural de la Sierra. Y también tuvieron en cuenta el principal componente histórico del paisaje del valle: la Cartuja del Paular. La parte dedicada a ella es la más amplia y la más minuciosa de las que componen el relato excursionista publicado en el Boletín de la Institución. La imagen de la Cartuja renueva las que existían con anterioridad, como la dieciochesca de Ponz y la romántica de Quadrado y La Fuente, y ofrece un modo mucho más moderno de entender la obra de arte, procurando describirla, caracterizarla y valorarla con rigor y precisión, sin excluir la parte de conexión personal, apoyada en la propia sensibilidad y en el propio gusto, que cabe poner en juego.

\section{La VALORACIÓN DE La GRANJA Y SU PAISAJE}

La excursión de julio de 1883 entró en la provincia de Segovia, como hemos dicho, por el puerto del Reventón. Visitaron La Granja de San Ildefonso y la ciudad de Segovia. Llegaron a La Granja a mediodía del martes 17, y comieron en la taberna de María la Pajarota. Tras descansar un rato en los bancos de la propia taberna, salieron al encuentro de Joaquín María de Castellarnau, que estaba entonces destinado allí como ingeniero de Montes de la Casa Real, que fue quien les acompañó en la visita del Palacio y unos días más tarde, tras su vuelta de la ciudad de Segovia, en la visita a los jardines. Castellarnau permaneció en 
La Granja desde 1872 hasta 1901, y estuvo directamente relacionado con la Junta para Ampliación de Estudios e Investigaciones Científicas, organismo que incorporó y prolongó los planteamientos de la Institución Libre de Enseñanza. Los excursionistas de 1883 visitaron el Palacio y los jardines de La Granja con Castellarnau, y esas visitas fueron el comienzo de la relación mantenida desde entonces con el lugar por diversos institucionistas.

El relato publicado en el Boletín institucionista no dice nada de la impresión que produjo a los excursionistas el Real Sitio de La Granja de San Ildefonso, con su valioso patrimonio histórico y artístico, ya que termina precisamente en el momento de abandonar la taberna de María la Pajarota, y antes, por tanto, de visitar el Palacio y los jardines. El relato de Madrid Moreno, por el contrario, sí se refiere a ello. Madrid Moreno había sido alumno de la Institución Libre de Enseñanza y, en el momento de la excursión, era vicesecretario de su Junta Facultativa. Luego fue catedrático en la Facultad de Ciencias de la Universidad de Madrid y jefe de la Sección de Anatomía Microscópica del Museo Nacional de Ciencias Naturales. Fue, por tanto, un institucionista de primera hora, y hay que suponer que compartía los criterios y opiniones de ese círculo. De ahí que sus comentarios sobre La Granja puedan resultar ilustrativos. «El Palacio -escribió- es de estilo francés, construido en tiempos de Felipe V, de muy mal gusto, abundando los muebles de estilo neoclásico, churrigueresco y moderno». $\mathrm{Y}$ de sus jardines dijo que eran «imitación, en pequeño, del de Versalles», que su estilo era «neoclásico, muy regular y geométrico todo», y que el agua de sus fuentes procedía «de la de los riachuelos de los alrededores que van a reunirse en un lago, poco más pequeño que el estanque del Retiro, pero de mayor profundidad» (Madrid Moreno, 1931: 219-220).

La opinión de Madrid Moreno no disimula, como se ve, su escasa simpatía por el Palacio de La Granja, que no parece aumentar mucho en su fría descripción de los jardines. Podríamos pensar que Madrid Moreno era un naturalista, poco ducho en apreciaciones artísticas y expresiones literarias, pero esa suposición se viene abajo cuando se lee lo que dice, por ejemplo, de la ciudad de Segovia, donde, sin ser un experto, aporta impresiones y valoraciones bastante más sentidas y favorables. Parece más razonable situar el juicio desfavorable de Madrid Moreno en las coordenadas historiográficas y estéticas generales de la Institución Libre de Enseñanza, francamente alejadas del significado -histórico y artístico- del Palacio de La Granja. En el terreno historiográfico, esas coordenadas se tradujeron en una interpretación de la historia de España que concedió una importancia sobresaliente y decisiva al papel desempeñado por Castilla en la formación de la nación, y que, en relación con ello, valoró muy favorablemente el pasado medieval castellano, en el que vio el origen de los mejores valores y cualidades del ser histórico español, al tiempo que estimó que después, desde los Reyes Católicos o desde los inicios de la Casa de Habsburgo, 
comenzó una larga decadencia que llegó, a grandes rasgos, hasta la Guerra de la Independencia. Buen ejemplo de ello es la interpretación ofrecida en ese sentido por Manuel Pedregal y Cañedo, que fue profesor y rector de la Institución Libre de Enseñanza, en sus Estudios sobre el engrandecimiento y la decadencia de España, publicados en 1878, donde afirmó que los valores de la España medieval fueron arrumbados por los Habsburgo y que hubo que esperar hasta la Guerra de la Independencia para que el pueblo español recuperase el sentido de su identidad colectiva (Fox, 1997: 42-43). Y Francisco Giner dijo, en una carta a Azorín de 1912, que la decadencia de España había comenzado con los Reyes Católicos, cuando se inició el abandono de las cosas del alma y del cuerpo que «nos viene hundiendo hasta el abismo de estupidez desalmada de Marruecos» (Azorín, 1920: 383).

Ese enfoque historiográfico se corresponde con el de carácter estético, que se tradujo en la preferencia por el arte medieval -románico y gótico- y el creciente desprecio hacia los estilos artísticos posteriores, hasta llegar a las formas barrocas y churriguerescas, que se consideraron aborrecibles. Como señaló LópezMorillas, las preferencias artísticas de Giner se escalonaron, en orden decreciente, coincidiendo con la secuencia temporal, del siguiente modo: 1) románico (encomio incondicional); 2) gótico (admiración más templada); 3) plateresco (indiferencia); 4) clásico o «grecorromano», como El Escorial (desdén); 5) barroco (desagrado); y 6) churrigueresco (execración) (López-Morillas, 1988: 98-99). Esta perspectiva historiográfica y artística es la que permite entender el escaso aprecio que logró, en principio, el arte dieciochesco de La Granja en el círculo gineriano e institucionista, que contrasta fuertemente con el gran interés y la muy alta valoración que ese mismo círculo dedicó, también en la Sierra de Guadarrama, a la Cartuja del Paular. Porque los institucionistas situaron siempre, en sus valoraciones, la Cartuja del Paular por delante de otros lugares de la Sierra de Guadarrama como el Palacio de La Granja de San Ildefonso, y también el Monasterio de El Escorial (Ortega Cantero y García Álvarez, 2009: 73-81). Y la razón de esa preferencia es que la Cartuja del Paular remitía - del mismo modo que lo hacía el castillo de Manzanares el Real, también del siglo XV, del tiempo de los Trastámaras- a la entidad castellana y medieval de la Sierra de Guadarrama, a la Sierra de «cuño caballeresco y castellano» de la que habló Unamuno. Después, sigue Unamuno, «vencida ya la caballería castellana», llegó El Escorial a la Sierra, con su «sello imperial, español, herreriano, rígido, majestuoso y monástico» (Unamuno, 1966: 594).

Distingue así Unamuno, por tanto, dos mundos diferentes -el castellano y caballeresco, por un lado, el español e imperial, por otro- y las preferencias de los institucionistas y de otros círculos intelectuales, tanto en términos históricos como estéticos, se inclinaban decididamente hacia el primero de ellos. Los institucionistas y sus seguidores contrapusieron su declarada simpatía por la 
Cartuja a su decidida animadversión hacia lo que La Granja significaba en términos históricos y artísticos. Frente a las cualidades atribuidas a la Cartuja, las características de La Granja les parecieron expresivas de un mundo decadente y muy alejado de los valores que consideraban nacionalmente fundamentales. Constancio Bernaldo de Quirós, que fue discípulo de Giner en la Universidad de Madrid y luego fundador y primer presidente de la Sociedad de Alpinismo Peñalara, y que se mostró siempre muy identificado con el ideario institucionista, ofreció algunos acabados ejemplos de esa contraposición entre un mundo y otro. En uno de los escritos de su librito titulado Peñalara, publicado en 1905, comparó «el falso clasicismo de la Granja», con sus jardines amanerados que «acaban por disgustaros», exponente de «un siglo frívolo y presumido», y el «gusto medioeval» del Paular, situado entre «magníficos pinares que preparan el espíritu para la contemplación del arte gótico que aguarda en el Monasterio» (Bernaldo de Quirós, 1905: 45-46). Y otra prueba de que La Granja no estuvo entre las preferencias históricas y artísticas de la Institución es que las numerosas excursiones dirigidas por José Giner Pantoja y José Ontañón Valiente en los años veinte y treinta, conectadas con el curso que daba en la Institución el primero desde 1922 sobre «Historia del Arte», tuvieron las ciudades históricas castellanas como destino de muchas de ellas, con una marcada predilección por Toledo y Segovia, pero nunca se detuvieron en La Granja.

Esta escasa simpatía hacia el significado histórico y artístico del Palacio de La Granja no quiere decir, sin embargo, que los institucionistas no valoraran en alto grado otras cualidades del lugar, como el carácter del sitio y, sobre todo, sus rasgos naturales y paisajísticos. Ello es lo que hizo que, tras el descubrimiento del verano de 1883 , fueran varios los institucionistas que se relacionaron directamente con La Granja, entre los que se contaron, en primer lugar, los que compraron casas en las que pasaron sus temporadas veraniegas, como sucedió, desde finales del siglo XIX, con tres destacados profesores de la Institución: los geólogos José Macpherson y Francisco Quiroga, y el astrónomo y meteorólogo Augusto Arcimís.

Macpherson y Arcimís mantuvieron una relación particularmente estrecha con La Granja de San Ildefonso. El primero, que tuvo su casa en el número 1 de la calle Calandria, fue un destacado geólogo, un notable fotógrafo ${ }^{2}$ y un consumado excursionista - «recorrió casi toda España y Portugal, especialmente sus regiones montañosas», escribió Eduardo Hernández-Pacheco-, fundador de la geología moderna española, que participó activamente, junto a otros geólogos

2. Su colección de fotografías formó parte del legado que recibió finalmente la Institución Libre de Enseñanza, donde desapareció, como tantas otras cosas de su sede, durante la guerra civil. Algunas de ellas pueden verse en la Guía alpina del Guadarrama de Constancio Bernaldo de Quirós (Madrid, Librería de Fernando Fe, 1902), quien agradeció expresamente a Francisco Giner la autorización para utilizarlas. 
extranjeros de la talla del americano James D. Dana y el austriaco Eduard Suess, con quienes se carteó regularmente, en el movimiento que en el último tercio del siglo XIX «transformó fundamentalmente las antiguas concepciones orogénicas» (Hernández-Pacheco, 1927: 280). Macpherson propuso la primera interpretación moderna de la génesis y la evolución de la Sierra de Guadarrama, e influyó directa e intensamente en la valoración que de su paisaje ofreció el círculo gineriano e institucionista.

Conoció a Francisco Giner durante el destierro de éste en Cádiz, en 1875, tras ser expulsado de su cátedra en la Universidad de Madrid a consecuencia de la «cuestión universitaria» provocada por el ministro Orovio, y mantuvieron desde entonces una estrecha amistad. Macpherson fue un acabado ejemplo de institucionista, participó muy activamente en las actividades de la Institución - donde fue profesor de Geología y Petrografía, y dirigió la ya mencionada Sociedad para el estudio del Guadarrama-, a la que donó, por mediación de Giner, receptor inicial de su legado, su biblioteca y su material científico, que se instaló finalmente en un nuevo pabellón levantado en 1909 al que se dio su nombre. Y fue precisamente Macpherson quien introdujo a Giner en el conocimiento geológico y naturalista, proporcionándole, como recordó Constancio Bernaldo de Quirós, la educación que necesitaba para «comprender la grandiosa tectónica de la tierra» (Bernaldo de Quirós, 1922: 186). La visión del paisaje de la Sierra de Guadarrama conformada inicialmente por Francisco Giner -y prolongada por la Institución Libre de Enseñanza-, con su doble dimensión naturalista y cultural, se apoyó en todo momento en la innovadora interpretación propuesta por Macpherson (Ortega Cantero, 2002).

Macpherson mostró un notable interés por el paisaje de la Sierra de Guadarrama y, dentro de ella, por el de La Granja, que supo valorar sobre todo en términos científicos, naturalistas, pero añadiendo también a veces algunas impresiones de índole estética. En la sesión de la Sociedad Española de Historia Natural del 8 de noviembre de 1893, que presidió Máximo Laguna, por ejemplo, presentó una nota sobre «Los fenómenos glaciares en San Ildefonso (Segovia)», que acompañó con una colección de dieciséis fotografías de los mismos que regaló a la institución. Aunque la interpretación que propuso, acorde con las ideas entonces generalizadas que atribuían a los episodios glaciares un alcance superior al que realmente tuvieron, no fue acertada, su escrito expresa con claridad su interés naturalista hacia el paisaje que rodeaba al Real Sitio, concretado en este caso, como él mismo señala, en «el espacio comprendido entre los dos arroyos llamados el Chorro grande y el Chorro chico, antes de juntarse ambos en la Dehesa de Navalizar» (Macpherson, 1893: 144). Y no fue ése el único testimonio de su acercamiento a este paisaje: en el marco de su más amplia consideración de la Sierra de Guadarrama - en cuya parte culminante distinguió, por ejemplo, «lechos de un bello color rojo más o menos granatífero» y «rocas 
granitoideas de singular belleza» (Macpherson, 1883: 345)-, había hablado algo antes, por ejemplo, de la «pintoresca comarca» en la que se encuentra el palacio de La Granja, ofreciendo una precisa y expresiva descripción de las grandes masas geológicas conformadoras de aquel ámbito:

Si se estudia la disposición de las grandes masas que forman el gran circo donde está edificado el palacio de San Ildefonso -escribe-, en la parte más elevada de la cordillera de Guadarrama, y al cual dominan las altas cumbres de Peñalara, las Dos Hermanas, Siete Picos y Montón de Trigo y abierto solamente para dar salida al río Valsaín por entre los dos cerros de Matabueyes y la Atalaya, se verá que lo que presta su principal relieve a esa pintoresca comarca es una gran masa granítica que alcanzando su mayor altura y desarrollo en el macizo de Siete Picos, desciende desde allí en forma lenticular al NE. hasta desaparecer a corta distancia del Real Sitio de San Ildefonso, en la base del ya mencionado cerro de la Atalaya.

Limitando esta masa granítica se ven dos hiladas de gneis que con el mismo buzamiento al SE. Descienden la una desde Montón de Trigo a la Atalaya cuyo contacto se encuentra con frecuencia interrumpido por considerables afloramientos de pórfidos cuarzosos, y la otra desde las Guarramillas viene formando la cresta culminante de la sierra hasta unirse a la primera en la base meridional de la Atalaya, descendiendo el contacto entre ambas formaciones desde los 2.100 metros en Peñacitores hasta sólo los 1.200, que es la cota del último contacto en la base del ya mencionado cerro (Macpherson, 1883: 346-347).

Arcimís, amigo de Macpherson, conoció también a Francisco Giner en 1875, durante su destierro en Cádiz, y ambos mantuvieron asimismo desde entonces una estrecha amistad, que dio lugar a una correspondencia regular que abarcó desde ese año hasta 1909. Sus más de 125 cartas están depositadas en la Real Academia de la Historia, y el historiador Luis García de Valdeavellano, nieto suyo, publicó y comentó hace algunos años una selección sumamente interesante de las mismas (Valdeavellano, 1980). A diferencia de Macpherson, que era de su misma edad, Arcimís era cinco años más joven que Giner, quien ejerció sobre él una honda influencia, que se expresa con claridad en esas cartas. Cuando se trasladó a Madrid, en 1884, Arcimís fue profesor de Física y Astronomía en la Institución Libre de Enseñanza, donde organizó un modesto observatorio astronómico y una estación meteorológica. Giner le apoyó decididamente en el desarrollo de su dedicación científica en el ámbito de la Astronomía y la Meteorología, y con su ayuda, verdaderamente decisiva, se fundó en Madrid, en 1887, siguiendo un proyecto elaborado por el propio Arcimís, el Instituto Central Meteorológico, del que fue, mediante oposición, su primer director (Anduaga Egaña, 2005). La casa de verano de Arcimís estuvo en el número 14 de la Travesía del Horno, y desde allí pudo desplegar su afición excursionista y su interés por el paisaje de los alrededores. A su dedicación profesional añadió, como Macpherson, una notable afición fotográfica, que desarrolló en buena 
medida en aquel lugar, del que dejó un considerable número de imágenes del propio sitio de La Granja -de su población, de su palacio y de sus jardines-, de otros lugares cercanos, como Valsaín y Segovia, y del paisaje de la Sierra de Guadarrama ${ }^{3}$. Arcimís fue así otro protagonista notable de la relación mantenida por el institucionismo, desde su primer contacto en la excursión de 1883, con La Granja de San Ildefonso.

Tras su muerte, en 1910, la casa de Arcimís en La Granja fue donada por sus hijos, al igual que su biblioteca y su material científico, a la Institución Libre de Enseñanza. «Es una casita recogida, modesta, amueblada y suficientemente capaz para albergar a una docena de personas -se dijo en el Boletín institucionista-: sitio admirable para que puedan instalarse grupos de excursionistas y colonos de la Institución» (Nota, 1915: 223). Y, efectivamente, la casa se utilizó desde entonces, al igual que la casa-refugio que tenía la Institución en El Ventorrillo, también en la Sierra de Guadarrama, para facilitar las excursiones de los alumnos, al tiempo que servía como lugar de descanso de algunos destacados institucionistas.

En el verano de 1915, estuvo en ella José Castillejo, secretario de la Junta para Ampliación de Estudios e Investigaciones Científicas, el organismo dependiente del Ministerio de Instrucción Pública y Bellas Artes fundado en 1907 y directamente inspirado, como señalamos antes, en el ideario educativo y científico de la Institución Libre de Enseñanza. Castillejo estuvo allí con sus dos hermanas durante un mes, desde el 29 de junio hasta el 28 de julio de 1915, y dejó en sus cartas algunos comentarios que, además de describir sucintamente la casa, expresan su agrado y su compenetración con el lugar y su paisaje. «La casa es encantadora -escribe en una de sus cartas a Manuel B. Cossío y Ricardo Rubio, del 29 de junio-. El jardín está muy cuidado. Las fuentes corriendo. Hay un pleno silencio en el barrio. Los muebles viejos, la escalera y los cuartos ingenuos y tranquilos». Recuerda inmediatamente después a Augusto Arcimís, a quien conoció «todavía fuerte en su vejez», y a Francisco Giner, que había muerto poco antes, en febrero de ese mismo año - «Cómo habría gozado viviendo aquí!»-, y añade algo que es sin duda importante respecto de su valoración del lugar, al que califica de «santuario», como otros lugares predilectos de la Institución: «No debemos interrumpir las peregrinaciones a estos santuarios (éste, la Sierra [de Guadarrama], San Vicente [de la Barquera]), donde se refresca y se rehace la tradición» (Castillejo, 1999: 240).

3. Su colección de fotografías, con más de 800 imágenes en formato estereoscópico, es hoy propiedad de la Fundación Duques de Soria de Ciencia y Cultura Hispánica, por donación de sus nietos, y está depositada en el Instituto del Patrimonio Cultural de España, en cuya página de internet puede verse. 

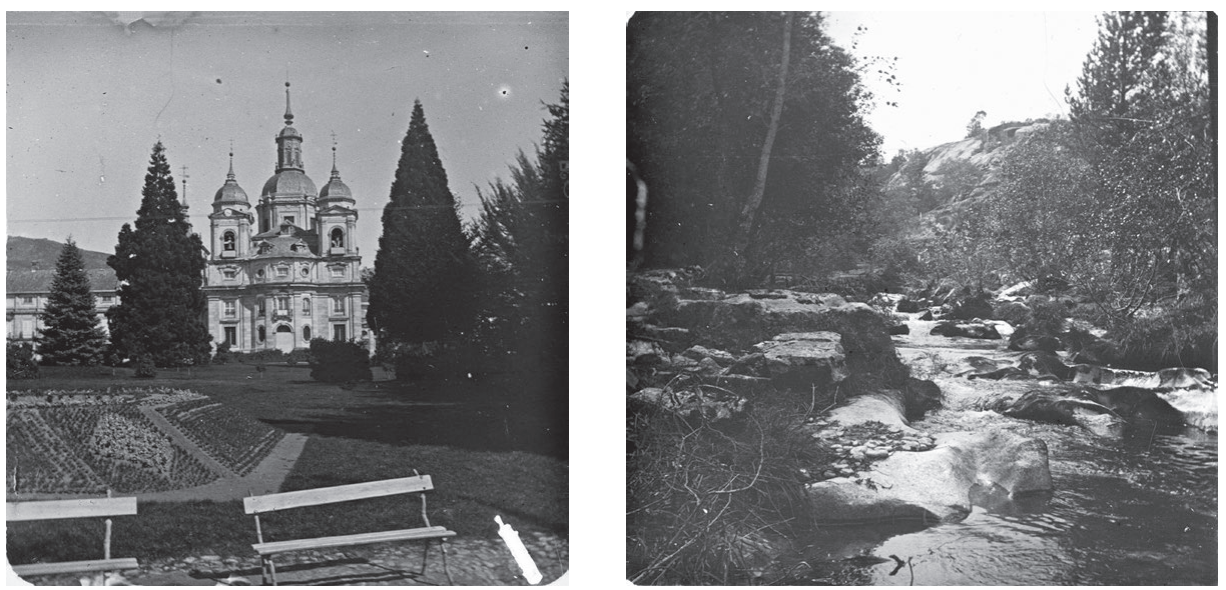

La Colegiata del Palacio de La Granja de San Ildefonso (izda.) y el río Valsaín, en la Sierra de Guadarrama (dcha.). Fotografías de Augusto Arcimís (Fundación Duques de Soria de Ciencia y Cultura Hispánica).

En otra carta, del 18 de julio, dirigida en este caso a su tío Rafael, dedica al paisaje de La Granja palabras elocuentes: «El sitio es muy hermoso. Está en la umbría de la gran sierra de Guadarrama, mirando a Segovia. Como el lugar es alto y hay abundancia de agua que corre por todas partes, hay mucho verdor, muchos pinares y robledos y muchas flores». Y añade una nota de sociedad: «Están aquí los reyes y sus hijos. Y Mariana y Concha [sus hermanas] se divierten porque los encontramos en todas partes, los tenemos al lado en el teatro y los vemos jugar al polo» (Castillejo, 1999: 241). Al escaso aprecio mostrado por los institucionistas hacia la dimensión histórica y artística de La Granja, representada por su Palacio y sus jardines dieciochescos, muy alejada de su ideario y sus preferencias en ese doble sentido, se opone su elogio de los valores naturales y paisajísticos del lugar, elevado por Castillejo a la categoría de «santuario» y lugar de «peregrinación». No en vano el paisaje de La Granja de San Ildefonso formaba parte del de la Sierra de Guadarrama, el más apreciado, en términos naturales, culturales y simbólicos, por el círculo gineriano e institucionista, y el más frecuentado en su intensa práctica excursionista.

Un año después, en los meses de julio y agosto de 1916, estuvo en esa misma casa de La Granja, con su hija Natalia, Manuel Bartolomé Cossío, sucesor de Francisco Giner al frente de la Institución Libre de Enseñanza. Las cartas que escribió desde allí contienen también algunas frases indicativas de su percepción del sitio. «Paso la mayor parte del día leyendo, escribiendo y contemplando tendido a la sombra de los robles en la ladera de la Peñalara», se lee en una de sus cartas a Ortega, del 4 de julio. Posteriormente, en una tarjeta postal para el mismo destinatario, fechada el 21 de agosto, dice con sentido del humor que, 
tras su reparadora estancia allí de más de mes y medio, corre el riesgo de convertirse en uno de sus olmos, «uno de estos recios, secos y solemnes olmos, a cuya sombra le escribo, imagen fiel -añade- de la tierra y la gente castellanas» (Otero Urtaza, 1994: 320-321).

La Institución Libre de Enseñanza utilizó además la casa de Arcimís en La Granja, al igual que la de El Ventorrillo, para facilitar las excursiones de sus alumnos por la Sierra de Guadarrama. Y a ello se sumó, ya en los años treinta, otro cauce de relación entre el mundo institucionista y el Real Sitio, a través de las Colonias Internacionales de Vacaciones que se desarrollaron allí, en sucesivos veranos, con la participación directa del Instituto-Escuela de Segunda Enseñanza, el centro educativo experimental creado en 1918 y dependiente de la Junta para Ampliación de Estudios. La primera de estas Colonias, cuya finalidad era realizar intercambios entre estudiantes españoles y estudiantes de otras nacionalidades, se organizó en el verano de 1931. El Consejo de Administración del Patrimonio de la República, responsable entonces de los bienes patrimoniales que habían pertenecido a la Corona, cedió en La Granja a la Junta para Ampliación de Estudios e Investigaciones Científicas la Casa de Oficios, el campo de polo, el campo de tiro y un estanque -habilitado como piscina- para una Colonia Internacional de Vacaciones. El Estado español pagaba los gastos en España de los profesores y alumnos extranjeros, y los alumnos españoles pagaban su estancia en España (120 pesetas), y residían gratuitamente en el extranjero, invirtiendo el sistema de pagos. Esta primera Colonia fue hispanoalemana y se realizó entre el 15 de julio y el 15 de agosto, con 30 escolares españoles -del Instituto-Escuela, organizador de la iniciativa, del Instituto del Cardenal Cisneros, de la Institución Libre de Enseñanza y del Colegio Alemány 20 escolares alemanes. Durante su estancia en La Granja, los colonos tuvieron clases de idiomas, lecturas, conferencias -dadas por profesores de la propia Colonia y por visitantes-, clases de cantos y música regional, paseos juegos y deportes, e hicieron excursiones a la Sierra de Guadarrama -a Peñalara, Fuenfría y Siete Picos-, El Escorial, Ávila y Segovia (Junta para Ampliación de Estudios e Investigaciones Científicas, 1933: 311-312). Las Colonias Internacionales de Vacaciones continuaron en los años siguientes, ocupándose de su organización la Junta de Relaciones Culturales del Ministerio de Estado, junto al InstitutoEscuela. Y desde 1932, el segundo verano de la iniciativa, los colonos fueron recibidos por el presidente de la República.

El alcance de las Colonias de La Granja se amplió a partir del verano de 1932, manteniendo la organización de clases, actividades y excursiones del primer año, con algunas mejoras, como la inclusión de salidas nuevas y de sesiones de cine educativo, contando con la colaboración del Patronato de Misiones Pedagógicas. En el verano de 1932, se realizaron en La Granja 3 Colonias: una hispano-alemana, entre el 5 y el 31 de julio, con 15 escolares de cada país; otra 
hispano-francesa, del 16 de julio al 16 de agosto, con 16 escolares españoles y 15 franceses; y, por último, otra hispano-inglesa, entre el 2 y el 24 de agosto, con 9 escolares españoles y 8 ingleses (Junta para Ampliación de Estudios e Investigaciones Científicas, 1933: 325-326). En los dos veranos siguientes, los últimos descritos en las Memorias de la Junta para Ampliación de Estudios e Investigaciones Científicas, se realizaron en la Granja dos Colonias: la hispanoalemana, en julio, con 23 y 15 escolares españoles y 24 y 23 alemanes, respectivamente; y la hispano-francesa, en agosto, que acogió a 29 escolares españoles y 20 franceses en 1933, y a 21 escolares de cada una de las dos naciones en 1934 (Junta para Ampliación de Estudios e Investigaciones Científicas, 1935: 442-444 y 489-491).

Las Colonias Internacionales de Vacaciones fueron el último episodio de la relación mantenida por la Institución Libre de Enseñanza y las instituciones directamente derivadas de ella -como la Junta para Ampliación de Estudios e Investigaciones Científicas y, bajo su dependencia, el Instituto-Escuela de Segunda Enseñanza- con el Real Sitio de La Granja de San Ildefonso. Relación que se inició en la primera excursión de la Institución a la Sierra de Guadarrama, en el verano de 1883, y que se prolongó después, ayudada por la adquisición de casas de verano en La Granja por parte de algunos destacados institucionistas de primera hora -José Macpherson, Francisco Quiroga, Augusto Arcimís-, y favorecida en buena medida por la donación a la Institución de la de Arcimís, tras su muerte en 1910, utilizada desde entonces para facilitar las excursiones serranas de sus alumnos y como lugar de descanso veraniego de algunos de sus responsables. Fue una relación ambivalente, caracterizada por la escasa simpatía hacia la dimensión histórica y artística dieciochesca del Real Sitio, alejada de las ideas y preferencias manifestadas en ese orden de cosas por el horizonte institucionista, y la simultánea admiración hacia los valores naturales y paisajísticos del lugar, expresión particular de la Sierra de Guadarrama. Y esa relación del círculo institucionista se prologó y amplió finalmente, en los años treinta, con la organización de las Colonias Internacionales de Vacaciones de La Granja, dependientes del Instituto-Escuela de Segunda Enseñanza, en las que convivieron escolares españoles, alemanes, franceses e ingleses.

\section{BIBLIOGRAFÍA}

AltamiRA, R. (1921): «El paisaje y los parques nacionales de España», en Boletín de la Institución Libre de Enseñanza, XLV, 736, pp. 220-222.

Anduaga EgAÑa, A. (2005): «La regeneración de la astronomía y la meteorología españolas: Augusto Arcimís (1840-1910) y el institucionismo», en Asclepio, LVII, 2, pp. 109-128.

Azorín (1917): El paisaje de España visto por los españoles. Renacimiento, Madrid, $181 \mathrm{pp}$. 
Azorín (1920): «Una carta de D. Francisco Giner de los Ríos», en Boletín de la Institución Libre de Enseñanza, XLIV, 729, pp. 383-384.

Azorín (1967): «Cossío» [1929], en Crítica de años cercanos. Taurus, Madrid, pp. 124-127.

Berdoulay, V. y Saule-Sorbé, H. (1998) : «La mobilité du regard et son instrumentalisation. Franz Schrader à la croisée de l'art et de la science», en Finisterra, XXXIII, 65, pp. 39-50.

Bernaldo De Quirós, C. (1905): Peñalara. Viuda de Rodríguez Serra (Biblioteca Mignon, XLV), $95 \mathrm{pp}$.

Bernaldo De Quirós, C. (1922): «La memoria de Don Francisco Giner», en Boletín de la Institución Libre de Enseñanza, XLVI, 740, pp. 185-187.

Besteiro, J. (1932): «En la inauguración de la Fuente de los Geólogos. IV. Palabras pronunciadas por D. Julián Besteiro, Presidente de las Cortes Constituyentes», en Boletín de la Institución Libre de Enseñanza, LVI, 868, pp. 239-240.

Castillejo, J. (1999): Epistolario de José Castillejo. III. Fatalidad y porvenir, 19131937. Cartas reunidas y enlazadas por David Castillejo. Castalia, Madrid, $715+$ CXVIII pp.

Cossío, Manuel B. (1932): «En la inauguración de la Fuente de los Geólogos. II. Palabras del profesor D. Manuel B, Cossío», en Boletín de la Institución Libre de Enseñanza, LVI, 868, pp. 237-238.

Cossío, Manuel B. (1985): Aproximación a la pintura española [1884]. Estudio preliminar y notas de Ana M. Arias de Cossío. Akal, Madrid, 188 pp.

DANIELS, S. y CosGrove, D. (1988): «Introduction: iconography and landscape», en Daniels, S. y CosGrove, D., eds.: The iconography of landscape. Essays on the symbolic representation, design and use of past environments. Cambridge University Press, Cambridge, pp. 1-10.

EXCURSIÓN (1886-1887): «Excursión durante las vacaciones del verano de 1883», en Boletín de la Institución Libre de Enseñanza, X, 237, p. 384, XI, 239, pp. 31-32, 243, pp. 95-96, 244, pp. 111-112, 245, pp. 127-128, 246, pp. 143-144, 247, pp. $159-160$.

Fox, I. (1997): La invención de España. Nacionalismo liberal e identidad nacional. Cátedra, Madrid, $224 \mathrm{pp}$.

Giner, J. M. y OntaÑóN, J. (1932): «Notas de excursiones», en Boletín de la Institución Libre de Enseñanza, LVI, 861, pp. 29-30.

Giner DE Los Ríos, F. (2004a): «El espíritu de la educación en la Institución Libre de Enseñanza» [1880-1881], en Obras selectas. Edición de Isabel Pérez-Villanueva Tovar. Espasa Calpe, Madrid, pp. 257-280.

GINER DE Los Ríos, F. (2004b): «Enseñanza y educación» [1881], en Obras selectas. Edición de Isabel Pérez-Villanueva Tovar. Espasa Calpe, Madrid, pp. 281-294.

Giner DE LOS Ríos, F. (2004c): «Paisaje» [1886], en Obras selectas. Edición de Isabel Pérez-Villanueva Tovar. Espasa Calpe, Madrid, pp. 792-801.

Hernández Pacheco, E. (1927): «El geólogo D. José Macpherson y su influjo en la ciencia española», en Boletín de la Institución Libre de Enseñanza, LI, 809, pp. 252-256, 810, pp. 280-284. 
JimÉnez, A. (1948): Ocaso y Restauración. Ensayo sobre la Universidad española moderna. El Colegio de México, México D. F., 311 pp.

Junta para Ampliación de Estudios e Investigaciones Científicas (1933): Memoria correspondiente a los cursos 1931 y 1932. Madrid, XV + 406 pp.

Junta PARA Ampliación de Estudios e Investigaciones Científicas (1935): Memoria correspondiente a los cursos 1933 y 1934. Madrid, XVI + 560 pp.

LópeZ-Morillas, J. (1972): «Preludio del 98 y literatura del desastre» [1962], en Hacia el 98. Literatura, sociedad, ideología. Ariel, Barcelona, pp. 223-253.

López-Morillas, J. (1980): El krausismo español. Perfil de una aventura intelectual. Fondo de Cultura Económica, México D. F., etc., 2. ${ }^{a}$ ed. revisada, 214 pp.

López-Morillas, J. (1988): Racionalismo pragmático. El pensamiento de Francisco Giner de los Ríos. Alianza, Madrid, 144 pp.

MACPHERSON, J. (1883): «Sucesión estratigráfica de los terrenos arcaicos de España», en Anales de la Sociedad Española de Historia Natural, XII, pp. 341-378.

MacPherson, J. (1893): «Fenómenos glaciares en San Ildefonso (Segovia», en Anales de la Sociedad Española de Historia Natural, Serie II, XXII: Actas de la Sociedad Española de Historia Natural, pp. 144-147.

Madrid Moreno, J. (1931): «Diario de una excursión realizada en el año 1883 a la Sierra de Guadarrama, Santander, Asturias y León», en Peñalara, 212, pp. 218-223, 213, pp. 241-243, 214, pp. 263-265.

Nota (1915): «Nota de Secretaría leída en la Junta general de Sres. Accionistas, celebrada el 31 de Mayo de 1915», en Boletín de la Institución Libre de Enseñanza, XXXIX, 664, pp. 221-223.

Ortega Cantero, N. (2001): Paisaje y excursiones. Francisco Giner, la Institución Libre de Enseñanza y la Sierra de Guadarrama. Caja Madrid y Raíces, Madrid, $333 \mathrm{pp}$.

Ortega Cantero, N. (2012): «Los valores del paisaje: la Sierra de Guadarrama en el horizonte de Francisco Giner y la Institución Libre de Enseñanza», en GARCíAVelasco, J. y Morales Moya, A., eds.: La Institución Libre de Enseñanza y Francisco Giner de los Ríos: nuevas perspectivas. 2. La Institución Libre de Enseñanza y la cultura española. Fundación Francisco Giner de los Ríos y Acción Cultural Española, Madrid, pp. 673-711.

Ortega Cantero, N. y García Álvarez, J. (2009): «Paisajes y lugares de memoria: Covadonga y El Paular», en Martínez de Pisón, E. y Ortega Cantero, N., eds.: Los valores del paisaje. Universidad Autónoma de Madrid y Fundación Duques de Soria, pp. 45-93.

Otero Urtaza, E. M. (1994): Manuel Bartolomé Cossío. Trayectoria vital de un educador. Prólogo de Julio Ruiz Berrio. Consejo Superior de Investigaciones Científicas y Asociación de Amigos de la Residencia de Estudiantes, Madrid, 420 pp.

Rochefort, R. (1978): «Le concept de paysage», en Géopoint 78. Concepts et construits dans la géographie contemporaine. Centre Littéraire Universitaire, Aviñón, pp. 243-250. 
Sociedad PARA El Estudio del GuAdarRama (1886): «La nueva Sociedad para el estudio del Guadarrama», en Boletín de la Institución Libre de Enseñanza, X, 236, pp. 367-368.

UnAmuno, M. de (1966): «Manzanares arriba, o las dos barajas de Dios» [1932], en Obras completas. I. Paisajes y ensayos. Introducciones, bibliografías y notas de Manuel García Blanco. Escelicer, Madrid, pp. 593-595.

Valdeavellano, Luis G. de (1980): Mi abuelo Augusto Arcimís y su correspondencia con don Francisco. El Instituto Central de Meteorología. Corporación de Antiguos Alumnos de la Institución Libre de Enseñanza, Madrid, 50 pp. 